\title{
Long-term Trends of Distribution and Regional Composition of Hatchery-released Juvenile Pink and Chum Salmon in the Sea of Okhotsk during the Fall of 2011-2017
}

\author{
Alexander V. Bugaev ${ }^{1}$, Alexandra I. Chistyakova ${ }^{1}$, and Shigehiko Urawa ${ }^{2}$ \\ ${ }^{1}$ KamchatNIRO (Kamchatka Institute of Fishery and Oceanography), Petropavlovsk-Kamchatsky, Naberezhnaya \\ street, 18, 683000, Russia \\ ${ }^{2}$ Hokkaido National Fisheries Research Institute, Japan Fisheries Research and Education Agency, 2-2 \\ Nakanoshima, Toyohira-ku, Sapporo 062-0922, Japan
}

Keywords: juvenile pink and chum salmon, hatchery origin, distribution, the Sea of Okhotsk, trawl surveys, otolith mark

The Sea of Okhotsk is the most important feeding area for juvenile pink and chum salmon of Asian origin during the first summer and fall (Radchenko et al. 2018; Urawa et al. 2018). General long-term tendencies of distribution and migration of hatchery-released juvenile pink and chum salmon in the basin of the Sea of Okhotsk in the fall of 2011-2017 were figured out as a result of otolith mark analysis for fish samples caught by the trawl surveys of TINRO-Center (Fig. 1). Otolith samples were collected from 6,924 pink and 9,870 chum salmon (Table 1). Subsamples to examine otolith marks were made at every station of trawling, where the number of juvenile fish in the catch was appropriate to take 50 individuals or so for the subsampling. The North Pacific Anadromous Fish Commission (NPAFC) otolith mark release database (http://npafc.taglab.org/arkSummary.asp) was used for the identification of hatchery origins. The statistics of the hatchery releases of otolith-marked pink and chum salmon in Russian Far East and Japan was also cited from the official data by NPAFC.

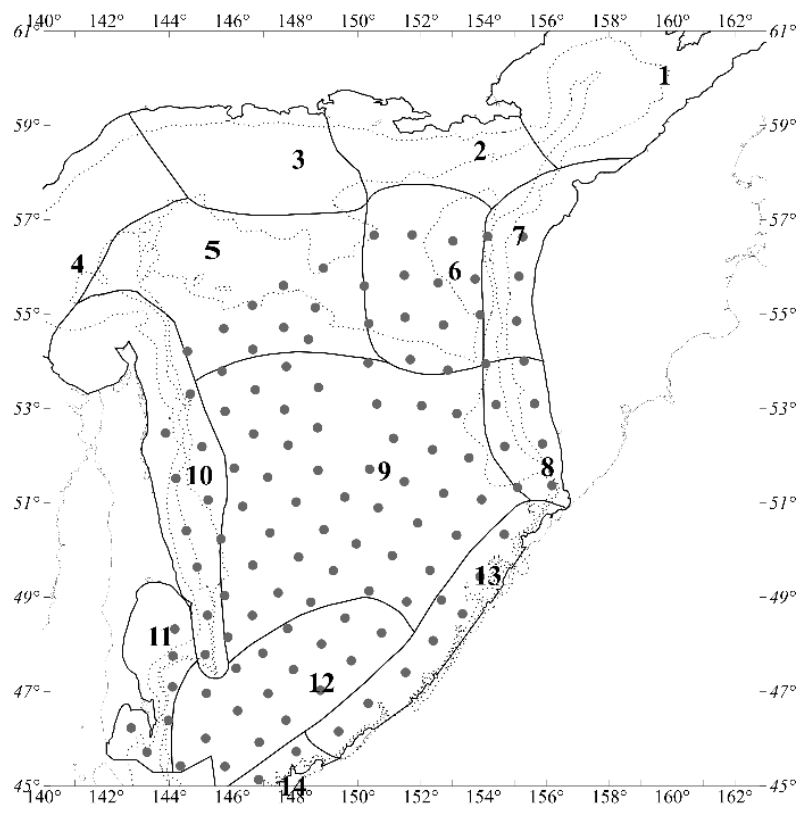

Fig. 1. The standard scheme of trawling stations in the fall complex pelagic surveys by TINRO-Center in the Sea of Okhotsk. Legend: the numbers and lines mark biocenotic districts of the research (Volvenko 2003).

Earlier studies suggested that stable tendencies in the dynamics of ocean currents in the Sea of Okhotsk induced the cyclic character of juvenile salmon migrations in the basin (Chistyakova and Bugaev 2013, 2016). Their suggestion mainly concerned pink and chum salmon from the southern coasts (Sakhalin, the Southern Kurile Islands, Hokkaido and Honshu). Considerable numbers of fish from this group migrated shifting in the north or northeast direction to the coast of West Kamchatka up to $55-57^{\circ} \mathrm{N}$, followed by later cyclic migration in the southwest or south direction toward the South Kurile Islands. Detailed schemes of juvenile salmon migrations in the Sea of Okhotsk off West Kamchatka were also made by other fish biologists (Yerokhin 2002; Varnavskaya 2006).

Our long-term data confirmed the cyclic fall migrations of juvenile pink and chum salmon in the Sea of Okhotsk (Fig. 2 and 3). At the same time the regional intraspecific composition of hatchery fish in the trawl catches was relatively stable at the level of interannual variations (Table 1). Both hatchery and wild fish might be engaged in the same migration process, because the distribution of marked fish coincided with the spatial structure of the 
total trawl catches by species. The detailed scheme of the distribution of juvenile salmon is consistent with the interannual variations of the migration intensity at the level of even or odd years.

Table. 1. Actual occurrence of regional origins of otolith-marked juvenile pink and chum salmon caught by the trawl surveys of the TINRO-Center in the Sea of Okhotsk during the fall of 2011-2017.

\begin{tabular}{|c|c|c|c|c|c|c|c|c|c|c|}
\hline \multirow[b]{2}{*}{ Species } & \multirow[b]{2}{*}{$\begin{array}{l}\text { Years of } \\
\text { survey }\end{array}$} & \multirow{2}{*}{$\begin{array}{c}\text { Total } \\
\text { number of } \\
\text { samples }\end{array}$} & \multicolumn{8}{|c|}{ Regional origins of otolith-marked fish } \\
\hline & & & $\begin{array}{l}\text { Kuril } \\
\text { Islands }\end{array}$ & Sakhalin & $\begin{array}{c}\text { Southwest } \\
\text { continental } \\
\text { coast }\end{array}$ & $\begin{array}{c}\text { Northern } \\
\text { continenta } \\
1 \text { coast }\end{array}$ & $\begin{array}{c}\text { Western } \\
\text { Kamchatka }\end{array}$ & Hokkaido & Honshu & Total \\
\hline \multirow[t]{8}{*}{ Pink } & 2011 & 730 & 21 & 9 & & & & & & 30 \\
\hline & 2012 & 894 & 10 & 4 & & & & 3 & & 17 \\
\hline & 2013 & 800 & 9 & 8 & & 1. & & 2 & & 20 \\
\hline & 2014 & 1,000 & 9 & 4 & & & & 2 & & 15 \\
\hline & 2015 & 750 & & 8 & & 4 & & 3 & & 15 \\
\hline & 2016 & 600 & & 11 & & 1. & & 3 & & 15 \\
\hline & 2017 & 2,150 & & 23 & & 9 & & 13 & & 45 \\
\hline & Total & 6,924 & 49 & 67 & 0 & 15 & 0 & 26 & 0 & 157 \\
\hline \multirow[t]{8}{*}{ Chum } & 2011 & 857 & 2 & 7 & & 3 & & 26 & 4 & 42 \\
\hline & 2012 & 2,370 & 15 & 24 & & 1 . & 4 & 140 & 29. & 213 \\
\hline & 2013 & 800 & 1 & 5 & & & 1 & 15 & & 22 \\
\hline & 2014 & 1,960 & 8 & 7 & & 1. & & 42 & 3. & 61 \\
\hline & 2015 & 1,073 & 2 & 14 & 4 & & & 22 & 2 & 44 \\
\hline & 2016 & 1,160 & & 22 & 2 & 2 & 3 & 20 & 1 & 50 \\
\hline & 2017 & 1,650 & & 26 & 1. & 6 & 1 & 40 & 3 & 77 \\
\hline & Total & 9,870 & 28 & 105 & 7 & 13 & 9 & 305 & 42 & 509 \\
\hline
\end{tabular}

Pink and chum salmon released from hatcheries in the south part of the Sea of Okhotsk (Sakhalin, the Southern Kuril Islands, Hokkaido and Honshu) might migrate north- and northeast-ward up to $55-57^{\circ} \mathrm{N}$ and to the coastal waters of the southwestern Kamchatka. Later juvenile fish migrated back in the south and southwest direction, reaching the south Kuril straits connecting to the North Pacific Ocean.

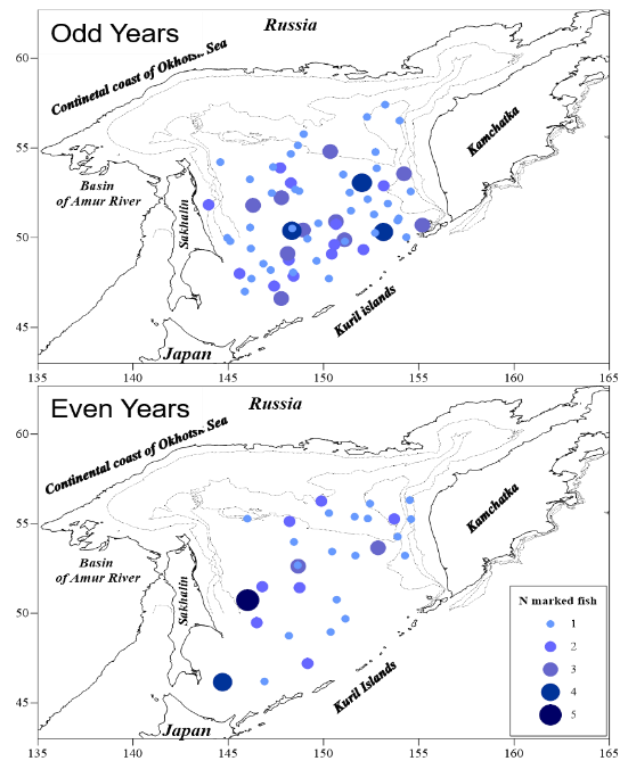

Fig. 2. Distribution of otolith-marked juvenile pink salmon in the Sea of Okhotsk during the fall of odd years (20112017) and even years (2012-2016).

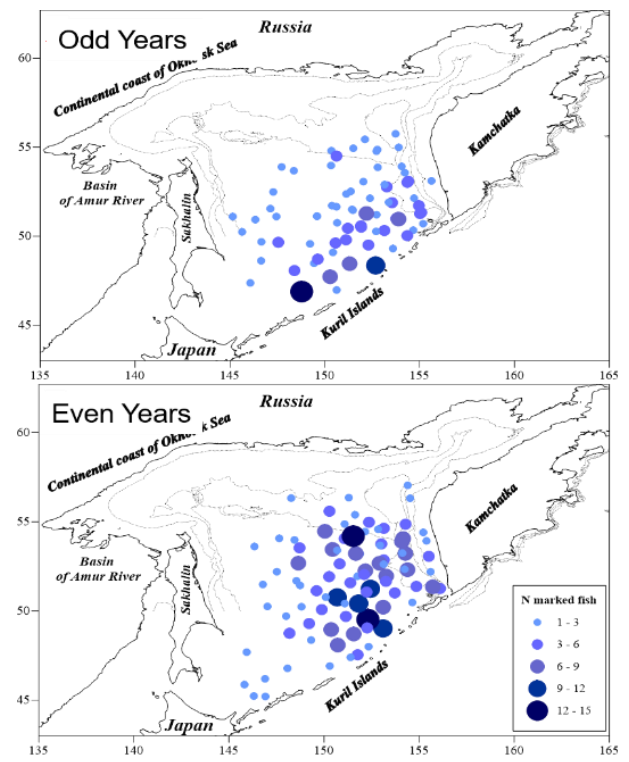

Fig. 3. Distribution of otolith-marked juvenile chum salmon in the Sea of Okhotsk during the fall of odd years (2011-2017) and even years (2012-2016). 
The density of hatchery pink salmon was higher in the central and eastern parts of the Sea of Okhotsk in odd years, and in the western and southern parts in even years (Fig. 2). The distribution of hatchery pink salmon strongly depends on production indices of major regional groups of hatchery stocks in Sakhalin and southern Kuril Islands. However, more researches are required for the tendency of pink salmon distribution, because the observation period examined in current work included the period when the dominant brood line of pink salmon shifted.

Most catches of hatchery chum salmon in the Sea of Okhotsk consisted of Japan and Sakhalin origins (Table). Otolith mark survey confirmed that juvenile chum salmon from all regional populations in Japan migrate into the Sea of Okhotsk (Chistyakova and Bugaev 2013), although their migration route is different by regional populations (Urawa et al. 2018). Spatial distribution of hatchery chum salmon may be affected by the abundance of pink salmon. In even years when West Kamchatkan juvenile pink salmon was not abundant, the density of hatchery juvenile chum salmon was higher in the central and eastern part of the Sea of Okhotsk (Fig. 3).

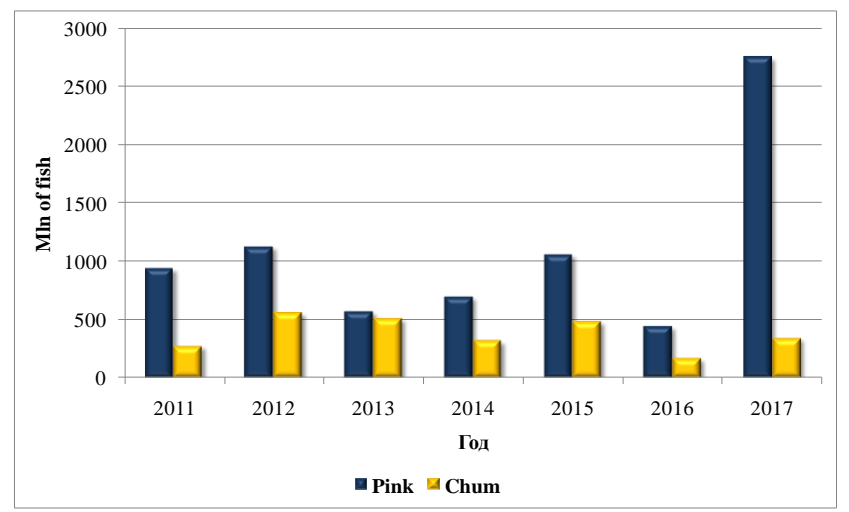

Fig. 4. Relative abundance (in million) of juvenile pink and chum salmon in the Sea of Okhotsk estimated by TINROCenter trawl surveys in the fall of 2011-2017.

Relative abundance of hatchery and wild juvenile chum salmon in the Sea of Okhotsk was evaluated based on the data for the dynamics of the total abundance of juvenile fish (Fig. 4), the ratio of otolith-marked fish in the catches, and the ratio of marked fish in hatchery-released fish, suggesting that wild fish were dominant in most years (Urawa et al. 2018). In addition, there was an attempt to evaluate the efficiency of hatchery systems in Russian Far East and Japan (Shevlyakov and Chistyakova 2017). However, the available data were not enough to evaluate the hatchery efficiency, because of insufficient number of otolith-mark releases from hatcheries in both countries. Therefore, future research in this field requires large-scale otolith-mark releases in Russia and Japan.

\section{REFERENCES}

Chistyakova, A.I., and A.V. Bugaev. 2013. Using the otolith marking results in identification of the origin and fall migration routes of hatchery pink and chum salmon in the Sea of Okhotsk. Izv. TINRO. 173: 77-102.

Chistyakova, A.I., and A.V. Bugaev. 2016. Evaluation of the origin and migration ways of hatchery pink and chum salmon in the basin of the Sea of Okhotsk in the fall period in 2011-2014. Researches of aquatic biological resources of Kamchatka and the northwest part of the Pacific Ocean. 40: 5-23.

Radchenko, V.I., R.J. Beamish, W.R. Heard, and O.S. Temnykh. 2018. Ocean ecology of pink salmon. In Ocean ecology of Pacific salmon and trout. Edited by R.J. Beamish. Am. Fish. Soc. Bethesda, Maryland. pp. 15160.

Shevlyakov, E.A., and A.I. Chistyakova. 2017. Migrations of juvenile chum salmon in the Sea of Okhotsk, comparative analysis of the activity efficiency of the hatchery systems of Russian Far East and Japan. Izv. TINRO. 191: 79-96.

Urawa, S., T.D. Beacham, M. Fukuwaka, and M. Kaeriyama. 2018. Ocean ecology of chum salmon. In Ocean ecology of Pacific salmon and trout. Edited by R.J. Beamish. Am. Fish. Soc. Bethesda, Maryland. pp. 161317.

Varnavskaya, N.V. 2006. Genetic differentiation of Pacific salmon populations. Petropavlovsk-Kamchatsky: KamchatNIRO. 488 pp.

Volvenko, I.V. 2003. Morphometric characteristics of standard biostatistical districts for biocenotic researches of fishery zone in Russian Far East. Izv. TINRO. 132: 27-42.

Yerokhin, V.G. 2002. Biology of juvenile Pacific salmon in the waters of the Sea of Okhotsk adjacent Kamchatka. Author's abstract. Ph.D. thesis. Petropavlovsk-Kamchatsky: KamchatNIRO. 24 pp. 